\title{
Detection of Delamination in Wall Paintings by Ground Penetrating Radar
}

\author{
Wanfu Wang \\ Dunhuang Academy \\ People's Republic of China
}

\section{Introduction}

Wall painting is an important part of cultural heritage. Generally speaking, painting on the wall of buildings or rocks, and those on the wall of caves are called wall paintings. But painting on the rock face is called rock painting. Wall painting on the building can be approximately classified into drawing murals, relief frescoes, mosaic murals and etcetera material paintings. Chinese ancient wall paintings can be generally distinguished according to different drawing site, such as palace paintings, temple paintings, grotto frescoes, coffin chamber murals, residential paintings and so on. Most of the paintings, including grotto frescoes, palace paintings or temple paintings, have several hundred years, or even several thousand years of history. During this time, under the influence of environmental factors (light, temperature, humidity, wind, sand and so on), biotic factors (micro-organism, insect), painting support walls and materials, architectural composition and human factor, wall paintings have undergone various kinds of diseases and damage. The most common painting diseases are delamination, flaking, disruption, smoking, pollution, deep-loss, paintlosses, cracks-hatch, mechanical-damage and so on.

Delamination is the loss of adhesion between layers in the support (wall, rock mass or others) and plaster stratigraphy, causing separation between plaster and suport. Delamination can occur between plaster layers, plaster and support. Generally, delamination causes painting surface crack and protrusion, even leads to painting losses because of gravity force from wall painting itself.

Literally speaking, Tibet is a region with abundance of cultural relics. According to an incomplete statistics, there are more than 2,000 ancient architectures all over the region, among which 3 are included in the world heritage list, 27 are national key preservation units, 55 are provincial level ones and 96 are city or county level ones. A primary survey shows such cardinal ancient architectures, just like Potala Palace, Norbulingka and Sagya Monastery, and the wall paintings are in severe need to be conserved. The architecture deterioration mainly occurs in the forms of structural distortion, roof leakage, rafter mildew, moth-eaten, rat-bitten beams, while the wall painting deterioration displays in delaminated plaster, pigment flaking, plaster and wall crevice, plaster disruption, soot and contaminant, among which the most serious damage, taking up more than $75 \%$ areas in total seems to be delamination [1]. In this sense, the great task in the conservation of Tibetan cultural relics proves to be the combat against the delamination in wall paintings. 


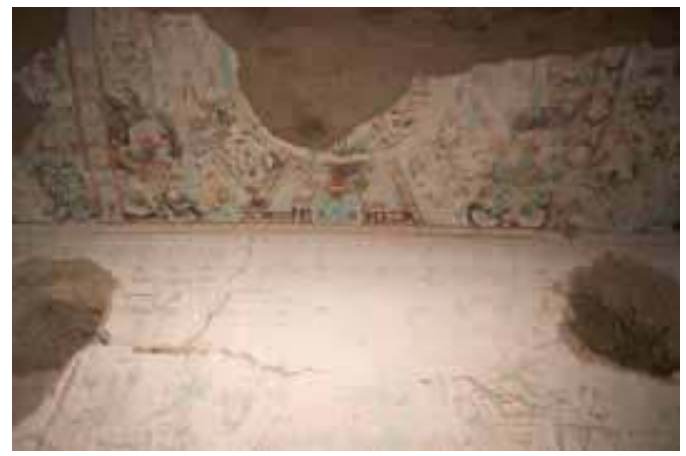

Fig. 1. Delaminated wall paintings in Cave 329 of Mogao Grottoes

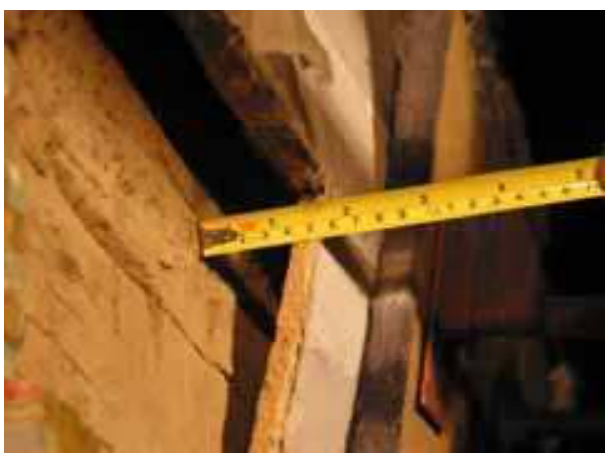

Fig. 2. Delaminated wall paintings in Eastern Audience Hall of Potala Palace

Wall paintings in Tibet Potala Palace, Norbulingka and Sagya Monastery were made as follows: firstly coarse red Argar earth was coated on the stone wall, rammed earth wall or light Bianma grass, secondly fine white Argar earth was coated on them, and then paintings were drawed, finally varnish or tung oil was spread on the wall painting surface.

The causes of wall painting delamination [2], [3] can be summed up in the following aspects: first of all, the construction material and crafts applied. The result of the survey discloses that the ancient Tibetan architectures are mixed constructures made of stone, earth and wood, which leaves the connection sections between the beams and wall paintings at the ceiling as well as the upper side of doors vulnerable to the delamination. The layerstructured wall paintings in those sections suffer distortion and breach under the pressure of vertical shearing stress, showing the unequal distribution of different interface stress upon different materials. The load of the building and roofing on beams and purlines transfers through those frameworks to walls. The wall painting plasters leaning against walls are directly connected to roofing. During the drying process, different materials displaying dissimilar contraction rates are easy to form gaps around the combining parts of those materials, which, in combination with the transmission of forces, contributes to the formation of the delamination.

Secondly, the cause comes to the layout of the architecture and the effects brought by both natural and human activity vibration. The structures of ancient Tibetan architecture mainly 
belong to pillar mixed load carrying members. In those architectures, the top of the architecture serves not only as the roofing of the floor but the platform for its upper floor. Besides used as passages and aisles, the Buddhist ceremony was also held here. Therefore, the vibration brought by the human activity is ranked among the causes for the formation of wall painting crevices and delamination. Each year the renovation of roofing is carried out regularly, during which a large number of people performing ramming generates strong vibration when they are ramming a new layer of Argar. This is also a potential threat to the supporting structure of roofing. In a word, the original layout of the structure leaves wall paintings open to deterioration, the deterioration of delamination in particular, while the human activity accelerates this process. The vibration produced by the human activity and the architecture weight itself are the direct cause of the mural delamination. In addition, the frequent earthquakes of different magnitudes also impose important effect upon the architecture, resulting in its distortion and damage.

Thirdly, the roof leakage is anther cause of delamination, which in turn is caused by the architecture distortion and the malfunction of the Argar layer.

Fourthly, the environment also contributes to the delamination. The surrounding environment of cultural relics is among the most important factors in their intact preservation. However, at the same time, it is also the prerequisite for the formation of deterioration. The environmental factors affecting the preservation of cultural relics mainly include temperature, moisture, illumination and ventilation, which in the case of the Tibetan palace wall paintings, are the indoor temperature and moisture plus region environment, such as air temperature, precipitation and air moisture. Researches show that the microenvironment of the Tibetan palace and temple are conducive to the preservation of wall paintings, whose annual mild changes to some degree avert the wall painting damage imposed by the freeze-thaw action.

In the conservation of wall paintings, it is quite a problem in technology to investigate the area and the degree of wall painting delamination. Traditionally, the diagnosis of delamination in grotto wall paintings and palace wall paintings is achieved by distinguishing the tone when tapping wall paintings by hand, such experience is useful in determining the area and degree of delamination, but it depends a lot on subjective sensation.

Non-destructive detection by ground penetrating radar (GPR) is the method of using highfrequency electromagnetic waves in the form of wide-band short pulse to transmit signal underground by the transmitting antenna of ground penetrating radar, which reflects back to the receiving antenna at the mismatching interfaces of electromagnetic impedence, and analysing the amplitude characteristics of received waves in time domain or frequency domain to distinguish abnormal body. Ground penetrating radar is widely used in archaeology, karst exploration, concrete pavement assessment, tunnel lining quality evaluation, subgrade stratification and so on. With the increase of central frequency of radar antenna and the using of ultra-wideband technology, ground penetrating radar is applied to the recognition of shallow target.

The depth of mural delamination is generally $2 \sim 5 \mathrm{~cm}$, rarely more than $10 \mathrm{~cm}$ (Fig. 3). Therefore, ground penetrating radar can detect depth of $20 \mathrm{~cm}$ to meet the requirements. Based on physical modeling experiment in the laboratory, the author uses the RAMAC GPR made in Sweden to detect delamination of wall paintings in Tibetan lamaseries and Lashao temple. During the in-situ test, the ground penetrating radar is equipped with a shielded 
antenna at the nominal central frequency of $1.6 \mathrm{GHz}$, the antenna is gently attached upon a piece of transparent parchment paper that has been covered on the vanishing surface of wall paintings, the sampling parameters of time window is set at $4 \mathrm{~ns}$ and sampling frequency at $142 \mathrm{GHz}$, and the signal triggering mode is adopted as distance or time. Having been processed by the band-pass filter and the filter of subtracting mean trace, the scope of delamination disease is determined and the thickness of wall painting delamination is estimated in the radar profile.

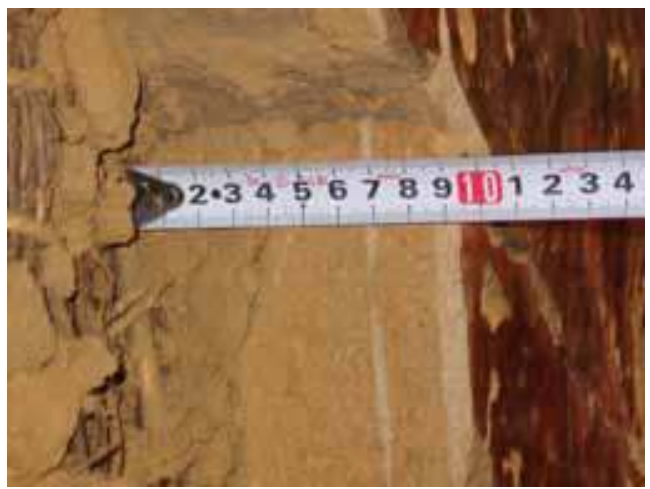

Fig. 3. Typical plaster section of wall paintings in Potala Palace

\section{Detection of delamination in replica plaster}

Under ideal condition, the vertical resolution limit is up to $1 / 10$ of electromagnetic wavelength, but under poor circumstance, the resolution is only $1 / 3$ of characteristic wavelength. As to the geotechnical detection by ground penetrating radar, it is typically considered $1 / 4$ to $1 / 2$ of impulsed electromagnetic wavelength as the vertical resolution to select the appropriate radar antenna. When the characteristic wavelength of electromagnetic waves is close to the thickness of cavity or delamination, the relative strong echo from the top or the bottom of cavity in the radar image is easy to identify. Because of the application of ultra-wideband radio technology, such kind of ground penetrating radar has higher resolution [4]-[7].

Replica of Tibetan wall painting plaster is made, and regular voids at different depth and with varied size are set inside, then the forward modeling detection is carried out in order to get appropriate parameters for acquisition of radar data, and to find effective filters for signal processing.

\subsection{Characteristic of transmitting impulse}

RAMAC GPR, made by MALÅ GeoScience in Sweden, is used to carry out the physical modeling experiment. It is designed on the basis of general modular, and it consists of control unit, antenna and computer terminals (Fig. 4). When detecting the delamination of wall paintings in Tibet Potala Palace, the $1.6 \mathrm{GHz}$ shielded antenna with the highest center frequency at that time was used. At present, the latest product, $2.3 \mathrm{GHz}$ radar antenna, takes a higher central frequency. As for the impulse electromagnetic wave generated by the transmitting antenna, its time domain (Fig. 5) and frequency domain (Fig. 6) characteristics 
affect the performance of ground penetrating radar, especially the vertical resolution of ground penetrating radar.

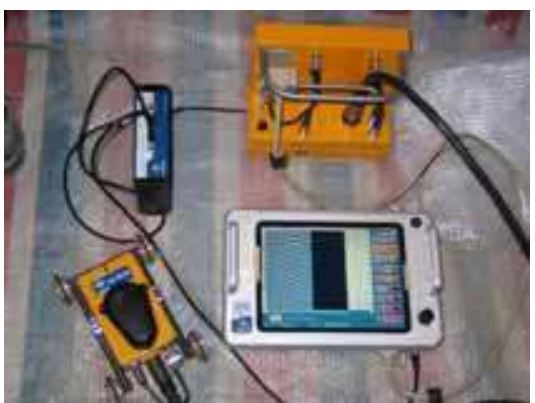

Fig. 4. RAMAC/GPR made by MALÅ GeoScience

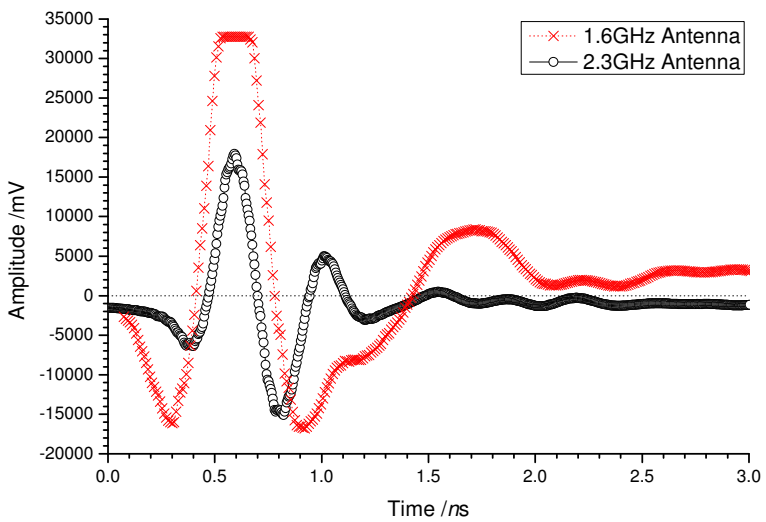

Fig. 5. Time domain waveform of carrier-free pulse emitted by GPR antenna

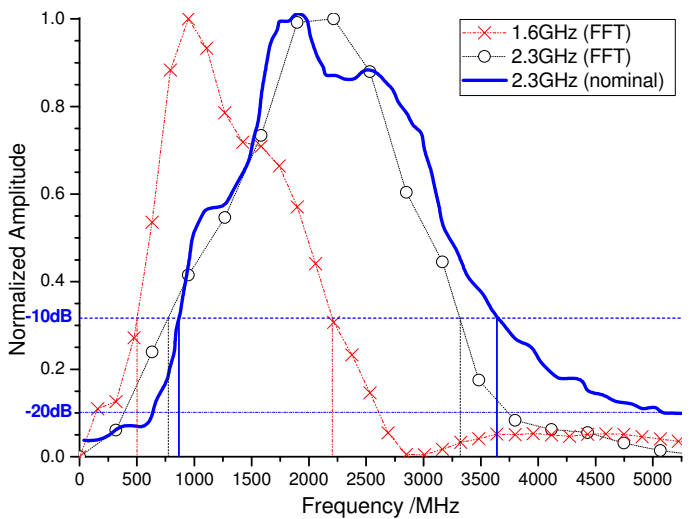

Fig. 6. Frequency domain spectrum of carrier-free pulse emitted by GPR antenna 
According to the Federal Communications Commission (FCC), the band width of impulse signal of electromagnetic wave is defined as the range of frequencies in which the signal's spectral density $\mathbf{P}(f)$ is above $-10 \mathrm{~dB}$ relative to its maximum:

$$
\mathrm{P}_{\mathrm{dB}}(\mathrm{f})=10 \cdot \log _{10}\left(\frac{|\mathrm{A}(f)|^{2}}{\left|\mathrm{~A}_{\max }\left(f_{\mathrm{c}}\right)\right|^{2}}\right) \mathrm{dB}
$$

where: $\mathbf{P}_{\mathrm{dB}}(f)$ is the normalized power when frequency is $f$ and the measuring unit is $\mathrm{dB} ; \mathrm{A}(f)$ is the amplitude when frequency is $f$ and $\mathrm{A}_{\max }\left(f_{c}\right)$ is the peak amplitude at the central frequency of $f_{\mathrm{c}}$.

When $\mathbf{P}_{\mathrm{dB}}(f)$ is $-10 \mathrm{~dB}, \mathrm{~A}(f)=10^{-1 / 2} \cdot \mathrm{A}_{\max }(f) \approx 0.32 \mathrm{~A}_{\max }(f)$. As shown in Fig. 6, when the normalized amplitude is 0.32 , its normalized power is equal to $-10 \mathrm{~dB}$.

In Fig. 6, the signals in time domain have been transformed into frequency domain by Fast Fourier Transform (FFT), the higher bound $f_{\mathrm{H}}$ and lower bound $f_{\mathrm{L}}$ of spectral band width of the electromagnetic wave transmitted by $1.6 \mathrm{GHz}$ antenna is $502 \mathrm{MHz}$ and 2,203 MHz respectively. As to $2.3 \mathrm{GHz}$ antenna, the higher bound $f_{\mathrm{H}}$ and lower bound $f_{\mathrm{L}}$ is $772 \mathrm{MHz}$ and 3,321 $\mathrm{MHz}$ respectively. The relative band width $\mathbf{B}$ is defined by the following equation:

$$
\mathrm{B}=\frac{f_{\mathrm{H}}-f_{\mathrm{L}}}{\left(f_{\mathrm{H}}+f_{\mathrm{L}}\right) / 2} \times 100 \%
$$

where: $\mathbf{B}$ is the relative band width of electromagnetic wave in frequency spectrum and the measuring unit is \%; $f_{\mathrm{H}}$ is the higher bound of the band width, $f_{\mathrm{L}}$ is the lower bound of the band width and both the measuring units are $\mathrm{MHz}$.

According to equation (2), it can be figured out that the relative band width of the $1.6 \mathrm{GHz}$ antenna is $126 \%$ and that of the $2.3 \mathrm{GHz}$ antenna is $125 \%$. So that, both of them belong to the type of ultra-wideband (UWB) antenna.

\subsection{Vertical resolution}

Having taken the technology of step frequency, RAMAC GPR expands the band width of impulse electromagnetic wave. The component of high frequency in the effective band width, $\mathbf{B}_{\text {eff, }}$ possess higher resolution. The simplified equation of the vertical resolution, $\Delta \mathbf{R}$, of the ground penetrating radar can be worked out according to the Rayleigh criterion:

$$
\Delta \mathrm{R}=\frac{v}{2 \mathrm{~B}_{e f f}}=\frac{c / \sqrt{\varepsilon_{r}}}{2 \mathrm{~B}_{e f f}}
$$

where: $\Delta \mathbf{R}$ is the vertical resolution of ground penetrating radar, also called as longitudinal resolution, its unit is $\mathrm{m} . \boldsymbol{v}$ is the propagating velocity of impulse electromagnetic wave in the medium, with the unit of $\mathrm{m} / \mathrm{s}$. $\mathbf{B}_{\mathrm{eff}}$ is the effective absolute band width in frequency spectrum of received signals and its unit is Hz. $c$ is the traveling speed of electromagnetic wave in vacuum, its value is about $3.00 \times 10^{8} \mathrm{~m} / \mathrm{s}$. $\varepsilon_{\mathrm{r}}$ is the real part of the relative dielectric constant of the medium.

By the equipment of Agilent 8510C single terminal vector network analyzer (VNA), it is determined that the relative dielectric constant of the fine layer, namely white Argar earth, and the coarse layer, namely red Argar earth, in wall painting plaster is about 3.76 and 2.9 
respectively in the frequency range of $0.2 \sim 3.0 \mathrm{GHz}$. As for $1.6 \mathrm{GHz}$ antenna, its absolute wide band is $1.70 \times 10^{9} \mathrm{~Hz}$, so that, according to equation (3), the vertical resolution is 0.051 $\mathrm{m}$, that is $5.1 \mathrm{~cm}$.

In equation (3), the half-wave length of the electromagnetic wave transmitting in the medium is regarded as the vertical resolution of ground penetrating radar. However, according to the Rayleigh criterion, $1 / 4$ of the wave length is regarded as the limit of the vertical resolution. Under high signal to noise ratio, 1/8 of the wave length can be regarded as the limit of the theoretical vertical resolution. In fact, the replacement of effective band width by absolute band width to calculate the vertical resolution is a comprised method. Because the detection of delamination in wall paintings by ground penetrating radar belongs to the application of ultra shallow layer in the depth range of $10 \mathrm{~cm}$, the two-way attenuation distance of electromagnetic wave in the dry plaster is relatively short. The component of high frequency with higher resolution can reflect back into the receiving antenna at the interface between plaster layer and cavity.

If the threshold of $-20 \mathrm{~dB}$ spectral density, in equal to normalized amplitude of 0.1 in Fig. 6 , is regarded as the recognition limit, the effective band width of $1.6 \mathrm{GHz}$ antenna in frequency domain is $121 \sim 2,624 \mathrm{MHz}$. Therefore, the minimum wave length of the electromagnetic wave transmitting in the wall painting plaster is $6.62 \mathrm{~cm}$. Then, the maximum theoretical vertical resolution of $\lambda / 8$ is about $8 \mathrm{~mm}$.

\subsection{Physical modeling experiment}

In order to determine the appropriate acquisition parameter of RAMAC GPR, and to obtain the method of digital signal processing (DSP), regular voids with different depth and thickness are made in the loam plaster (Fig. 7). The ground penetrating radar equipped with $1.6 \mathrm{GHz}$ shielded antenna is used to carry out the lab test (Fig. 8, Fig. 9, Fig. 10, Fig.11).

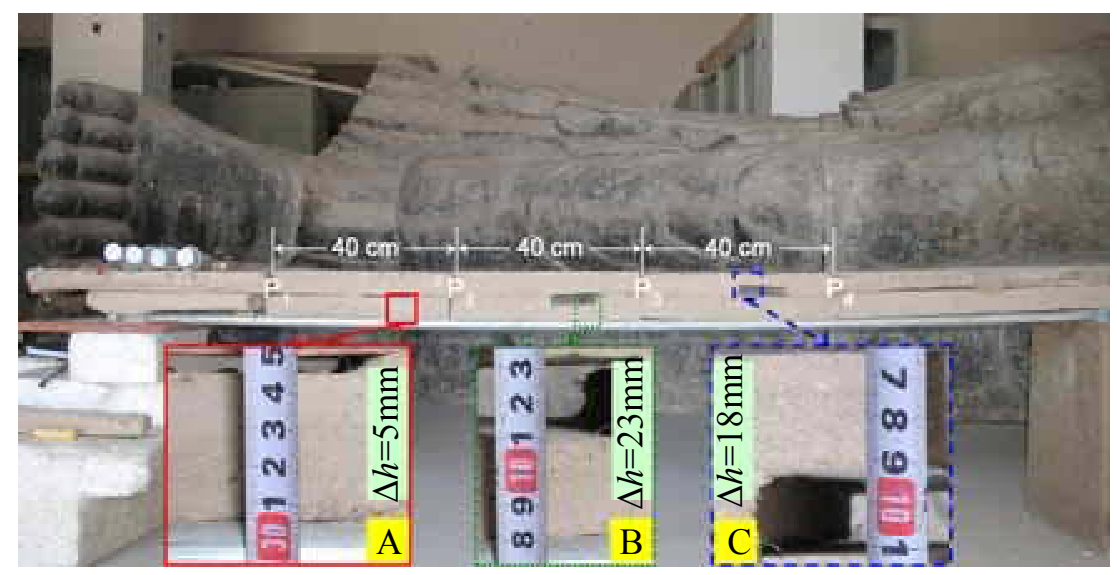

Fig. 7. Schematic layout of rectangular voids in plaster replica for detection by GPR

In Fig. 7, the length of the delamination parts A, B, and C is $100 \mathrm{~mm}$. Their buried depth $h$ and thickness $\Delta h$ is $45 \mathrm{~mm} \& 5 \mathrm{~mm}, 45 \mathrm{~mm} \& 23 \mathrm{~mm}$ and $27 \mathrm{~mm} \& \mathrm{~mm}$ respectively. The relative dielectical constant of the loam plaster is about 1.74, so that the propagation velecity 
of the electromagnetic wave in such medium is $2.27 \times 10^{8} \mathrm{~m} / \mathrm{s}$, namely $0.227 \mathrm{~m} / n \mathrm{~s}$ or 227 $\mathrm{m} / \mu \mathrm{s}$. It is faster than that of the electromagnetic wave in dry clay.

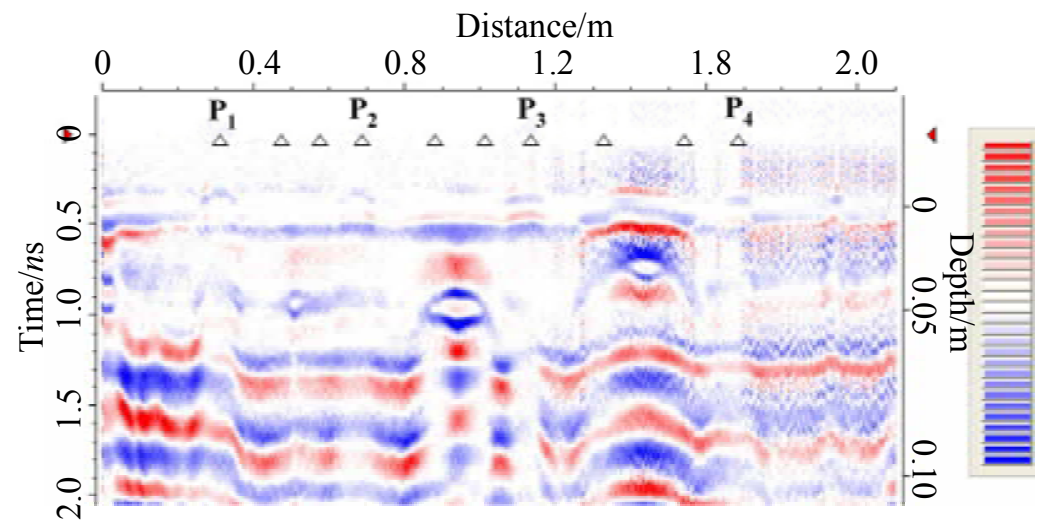

Fig. 8. Presentation of post-processed GPR profile in software of Ground Vision

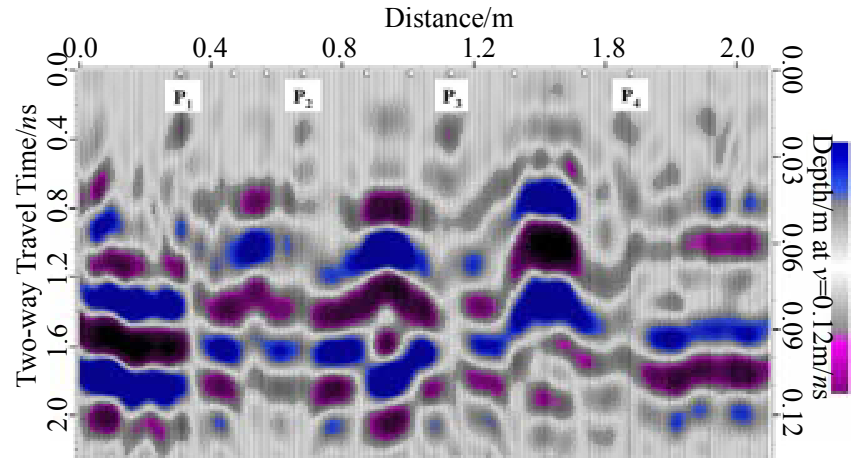

Fig. 9. Post-processed GPR profile in combination of wiggle mode and point mode

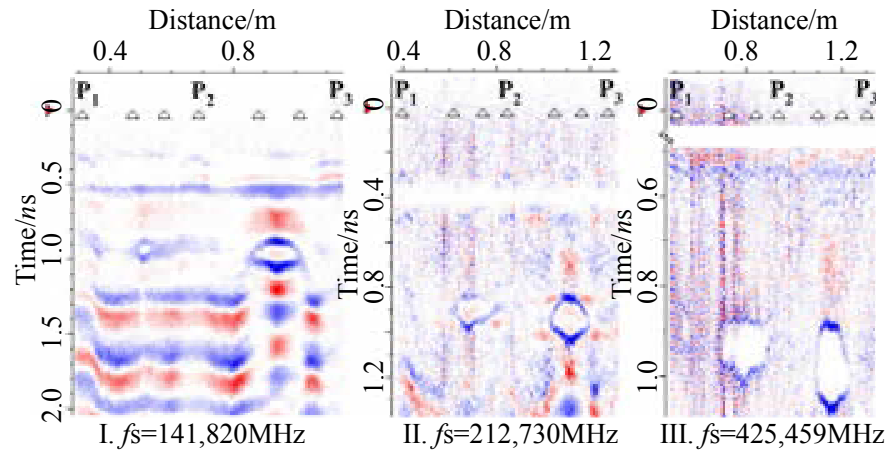

Fig. 10. FIR filtered GPR profiles at different sampling frequency 
In Fig. 8, the length of the radar profile is about $2.1 \mathrm{~m}$, the interval of the triggering time is $0.1 \mathrm{~s}$, the total time spent is $62.1 \mathrm{~s}$, and 621 traces of data have been collected. The average speed of the antenna is about $3.38 \mathrm{~cm} / \mathrm{s}$. The time window $t$ of the profile is $2.26 \mathrm{~ns}$, the sampling frequency, $f_{\mathrm{s}}$, is $141.82 \mathrm{GHz}$. The number of samples, $N$, collected in each trace is 320 , which is figured out by the following equation:

$$
\mathrm{N}=f_{\mathrm{s}} \cdot t
$$

What is shown in Fig. 8 is a radar profile, presented in the form of a matrix with 320 rows and 621 columns after loading the filter of finite impulse response (FIR). In the Ground Vision, which is a software affiliated to the ground penetrating radar equipment, through the processing of direct current (DC) removal, band pass filtering and subtract mean trace, the delamination in replica plaster can be distinguished clearly in the point mode of radar profile. Since the delamination A is not that thick, it is difficult to be located in Fig. 8. The delamination $C$ is so shallow that the noise over the echo is strong. The delamination $B$ is the most obvious and its thickness, $\Delta h$, can be calculated with the following equation:

$$
\Delta h=c \cdot \frac{\Delta t}{2}=c \cdot \frac{\left(\mathrm{N}_{t}-\mathrm{N}_{0}\right) \cdot t}{2 \mathrm{~N}}
$$

where: $\Delta h$ is the thickness of the delamination with the unit of $\mathrm{m} . c$ is the propagation velocity of electromagnetic wave in the delaminated area and the value is about $3.00 \times 10^{8}$ $\mathrm{m} / \mathrm{s}$. $\Delta \mathrm{t}$ is the two-way travel time when the electromagnetic wave propagates in the delaminated area and its unit is $\mathrm{s} . \mathbf{N}_{\mathrm{t}}$ is sample number of the lower surface of delamination in typical trace. $\mathbf{N}_{0}$ is sample number of the upper surface of delamination. $\boldsymbol{t}$ is time depth of the whole trace with the unit of s. $\mathbf{N}$ is sample number of the whole trace.

In equation (5), $t$ is $2.26 \times 10^{-9} \mathrm{~s}$. According to the characteristic waveform of delamination $\mathrm{B}$ in time domain, $\mathrm{N}_{\mathrm{t}}$ and $\mathrm{N}_{0}$ is 179 and 155 respectively, and $\mathrm{N}$ is 320 . The thickness of the delamination is figured out as $0.0254 \mathrm{~m}$, namely $25.4 \mathrm{~mm}$. It is very close to the actual thickness in replica plaster. By the same rule, $\mathrm{N}_{\mathrm{t}}$ and $\mathrm{N}_{0}$ for delamination $\mathrm{C}$ is 141 and 123 respectively, and its thickness is calculated as $19.1 \mathrm{~mm}$.

Fig. 9 is the interpretation result of the same radar profile in software of REFLEX after the processing of subtract DC shift, band pass butterworth, background removal and F-K migration. It is the combination of presentation in point mode and wiggle mode. The delamination parts of $\mathrm{A}, \mathrm{B}$ and $\mathrm{C}$ are obvious. Compared with the background, their common characteristics are the sudden increase in negtive amplitude and the phase inversion.

Fig. 10 is the interpretation result of delamination $\mathrm{A}$ and $\mathrm{B}$ at different sampling frequency. The higher the sampling frequency is, the more samples in illustration of delamination at the same time depth are. The bigger the difference of two way travel time between the upper and the lower surface of delamination is, the more serious the delamination is.

The results of modeling detection (Table 1) show that when the antenna couples well with the wall painting surface, the delamination in the radar profile is great clear. The higher the sampling frequency is, the more samples corresponding to the bound of delamination there are. This is good for the interpretation of radar profile, and the values of delamination thickness, figured out by equation (5), are close to each other. 


\begin{tabular}{|c|c|c|c|c|c|}
\hline \multirow{3}{*}{ Delamination } & \multicolumn{2}{|c|}{ Replica dimension } & \multicolumn{3}{c|}{ Calculated thickness/mm } \\
\cline { 2 - 6 } & \multirow{2}{*}{ Depth/mm } & \multirow{2}{*}{ Thickness/mm } & \multicolumn{3}{c|}{ Sampling frequency/GHz } \\
\cline { 4 - 6 } & & & 142 & 213 & 425 \\
\hline A & 45 & 5 & 16.5 & 19.2 & 15.6 \\
\hline B & 45 & 23 & 25.4 & 26.6 & 26.3 \\
\hline C & 27 & 18 & 19.1 & N/A & N/A \\
\hline
\end{tabular}

Table 1. Interpreted thickness of delamination in comparison to nominal size

\subsection{Analysis of typical traces}

The typical wave forms (Fig. 11, Fig. 12) of delamination A with the thickness of $5 \mathrm{~mm}$, delamination $\mathrm{B}$ of $23 \mathrm{~mm}$ thick and background are extracted from the radar profile. The comparison and analysis of transformed wave forms in time domain are presented in Fig. 13 and Fig. 14.

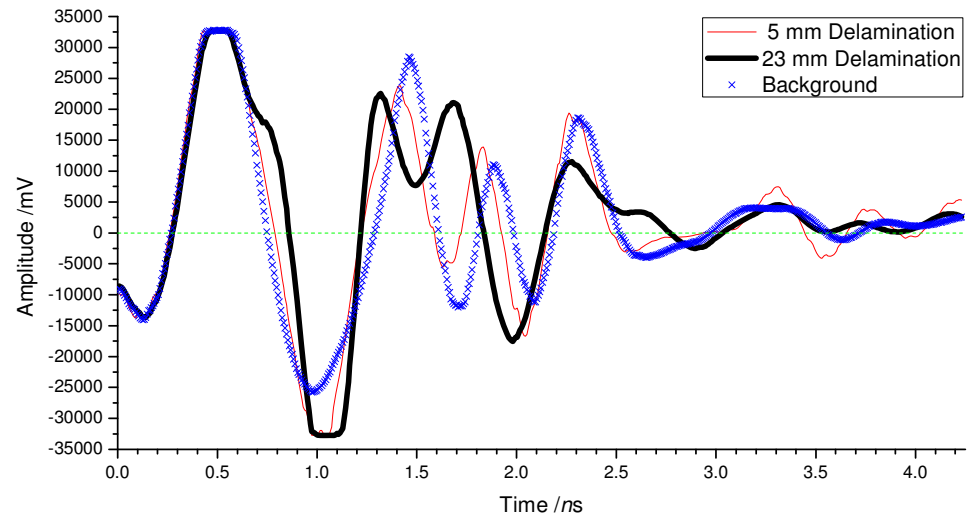

Fig. 11. Characteristic traces in time domain at sampling frequency of $142 \mathrm{GHz}$

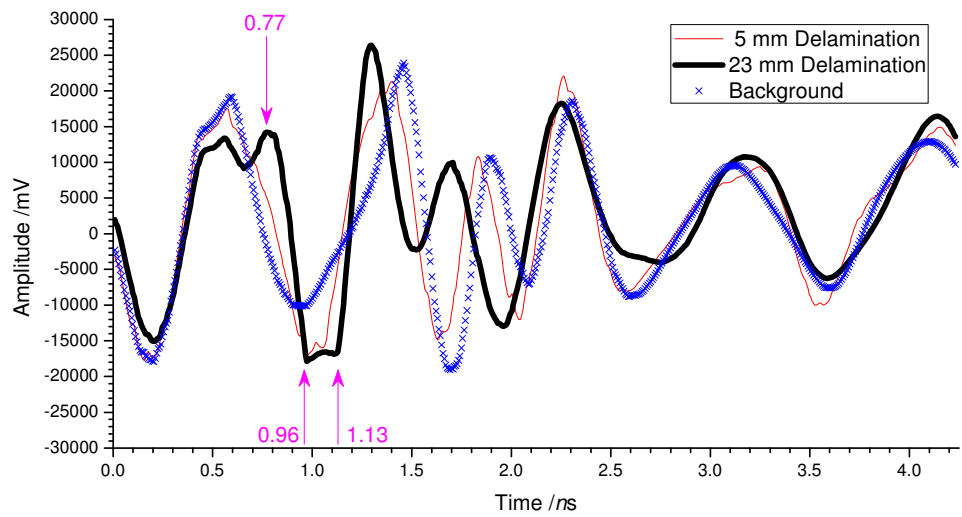

Fig. 12. Comparison of typical traces after high pass at $1.2 \mathrm{GHz}$ in time domain 


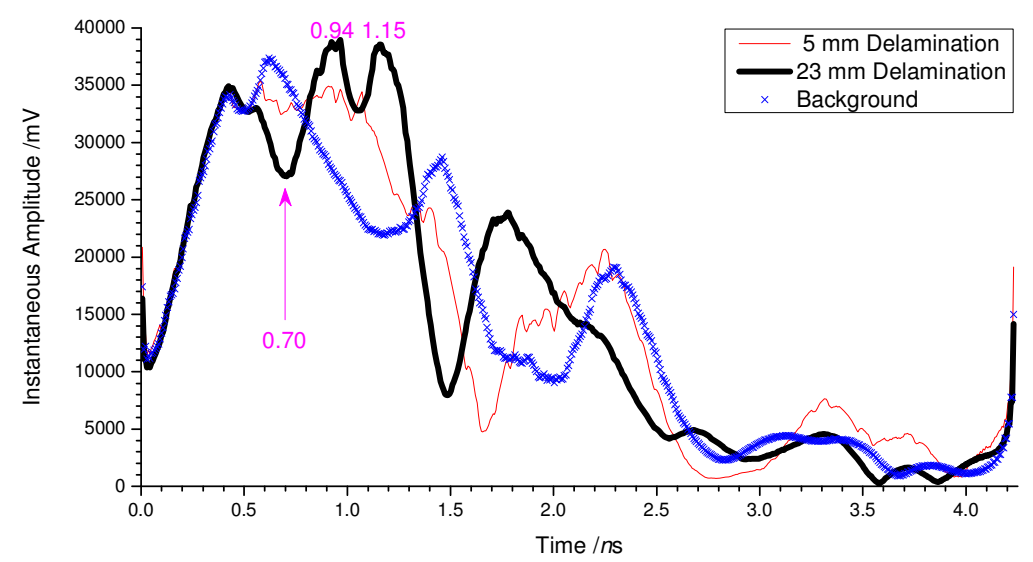

Fig. 13. Comparison of instantaneous amplitude after Hilbert transform

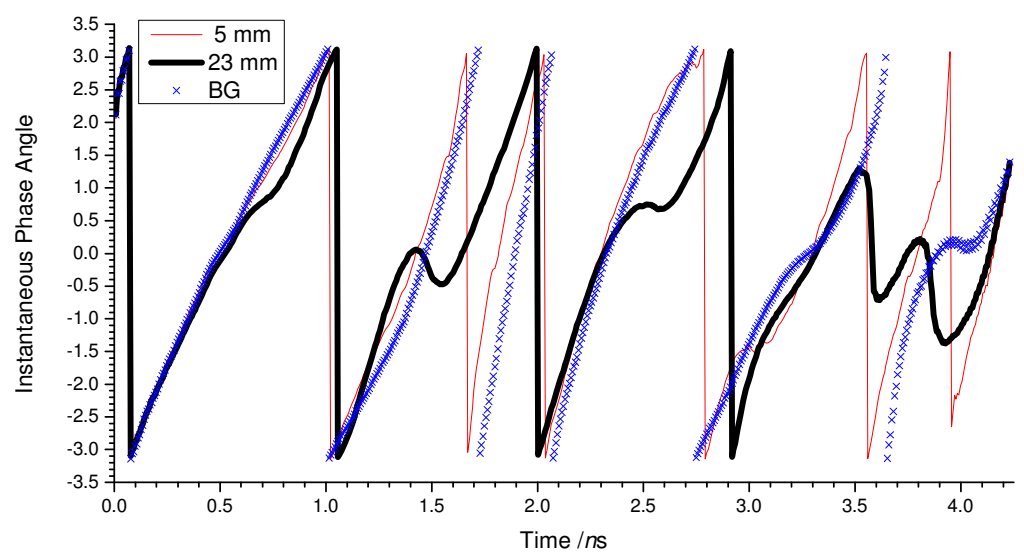

Fig. 14. Comparison of instantaneous phase after Hilbert transform

At the upper and lower interfaces of delamination, the instantaneous amplitude as well as the instantaneous phase of the delamination and the background in time domain go through alienation. The two way travel time is $0.7 n$ s and $0.9 n$ s respectively when the contrast is great, which is in consistent with the contrast of original waveforms in time domain.

Specifically to RAMAC/GPR and its accessory software of Ground Vision, it is suggested that the depth of time window should be about 3 ns and sampling frequency about 213 GHz. As a rule, the thickness of wall painting plaster in Tibetan lamaseries is less than 10 $\mathrm{cm}$, and it depends on efficient removal of direct coupled waves in radar profile to detect delamination beneath wall painting plaster. As the GPR raw data is processed by applying filter of finite impulse response (FIR), delamination in wall paintings is characterized as sudden amplification of negative amplitude in waveform, and the extent of delamination is proportional to the time difference of two adjacent troughs, representing how serious the deterioration is. 


\section{In-situ detection of delamination in wall paintings}

According to characteristic phenomena discovered and practical experience got in previous modeling experiment, GPR is applied to detect delamination in wall paintings in Potala Palace, Norbulingka and Sagya Monastery in Tibet. It is shown that strong negative amplitudes appear on certain GPR traces, which is in accordance with existence of serious delamination in wall paintings in these Tibetan lamaseries. Delamination in wall paintings in the Western Hall of Potala Palace is in great relation with wooden beam between plaster and blockstone wall. In the Mandala Hall of Sagya Monastery, delamination spreads from the top area of rammed wall, and it is proven to be more serious in the upper area.

\subsection{Detection in Sagya Monastery}

Visual inspection by means of video probe (Fig. 15) shows that delamination in wall paintings in the Sagya Monastery is very serious. The delamination is mainly distributed at the top of walls, usually in the form of wall painting plaster delaminating from the rammed plaster (Fig. 16).
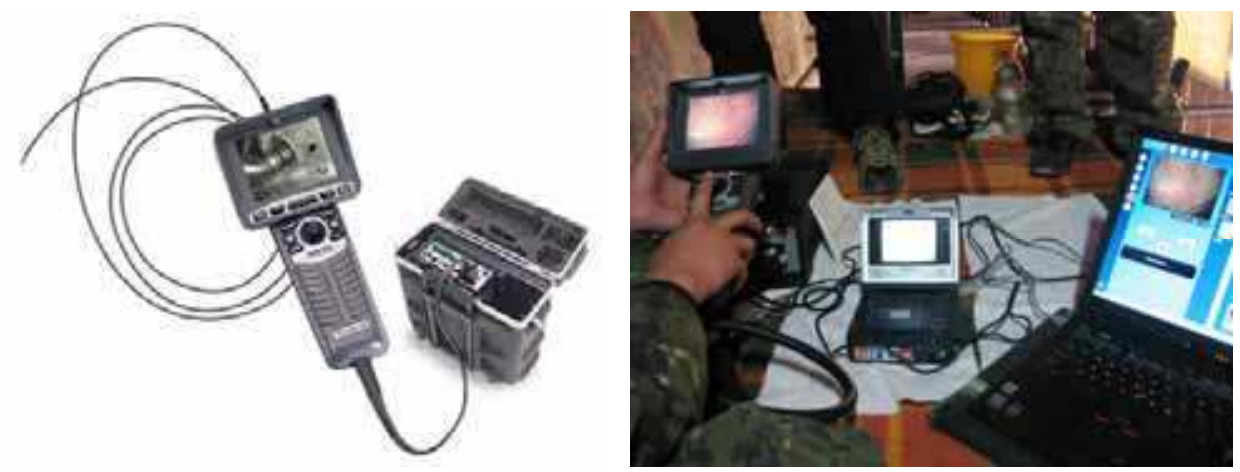

Fig. 15. XL PRO Video probe made by EverestVIT for remote visual test
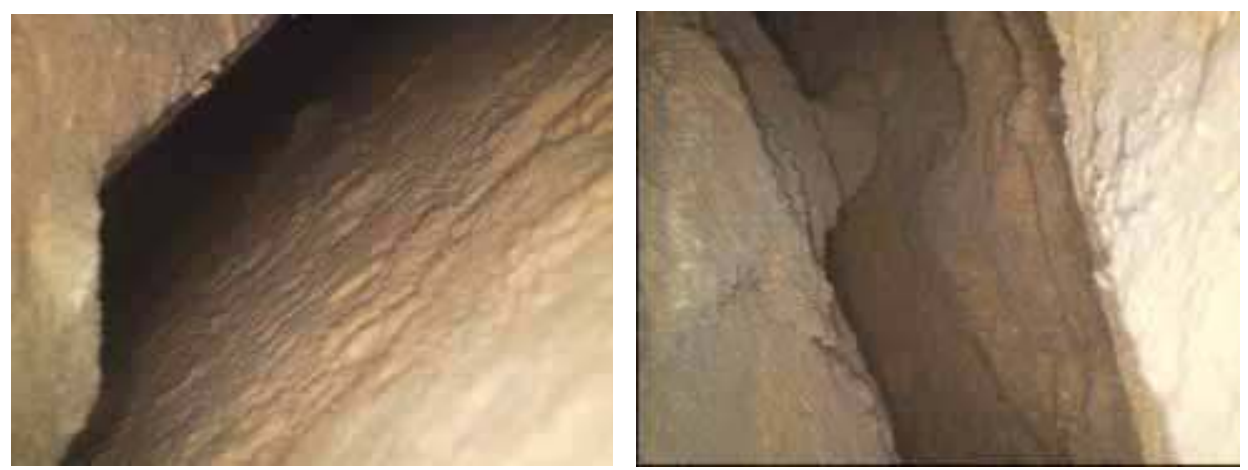

Fig. 16. Visualization of delamination in wall paintings by EverestVIT VideoProbe 
It has been proven by video probe that the delamination in wall paintings around the probing holes is thick. The three holes (Fig. 17) are connected with each other in that when it is blown at one hole the dust come out from the other two holes. It is a pity that although the interior condition of the delamination can be visualized and imaged by probing test, the thickness of the delamination can not be determined without reference. Only the existence of the delamination can be ensured. The around area (Fig. 18) is selected as the site of field test for detection.

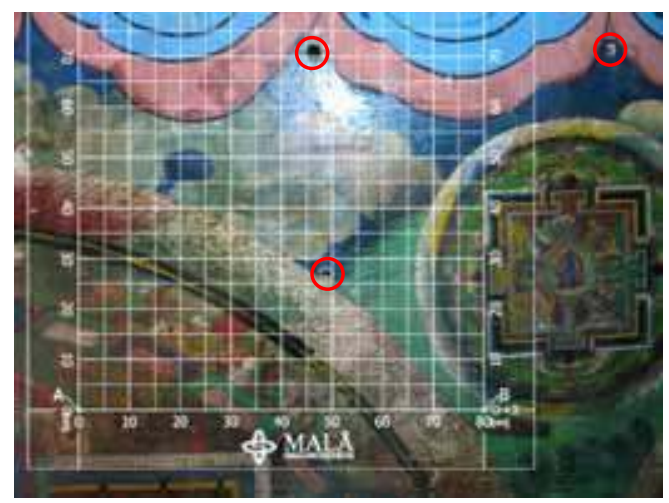

Fig. 17. Relative position of detection area to probing holes

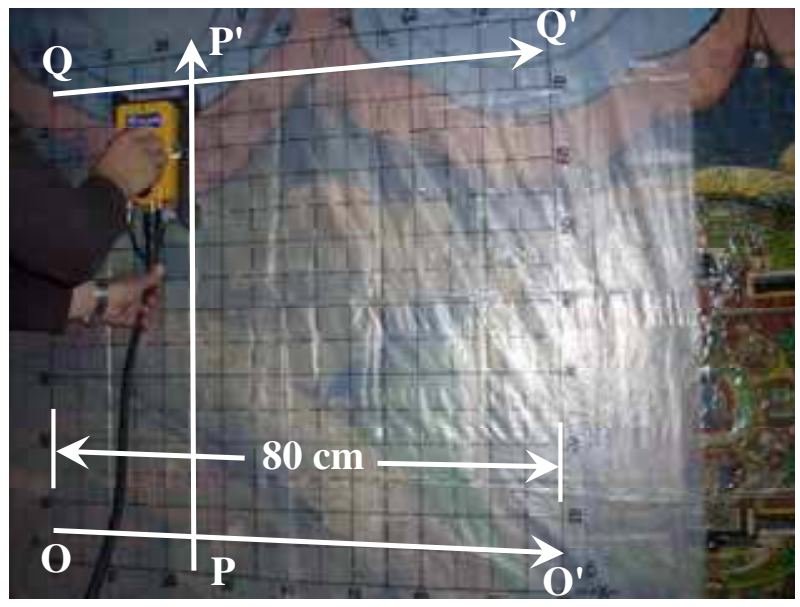

Fig. 18. In-situ detection of delamination in Mandala Hall of Sagya Monastery

The field test for detection of delamination in wall paintings was carried out on August 7 , 2007. Test parameters were as follows: the sampling frequency is $60779.928037 \mathrm{MHz}$, interval of triggering distance is $0.002590 \mathrm{~m}$ and the depth of time window is $5.528141 \mathrm{~ns}$. In the post-processing software of Easy 3D, as the radar profile is filtered by FIR, it is found that the delamination at the top is more serious than that at the bottom in the west wall (Fig. 19). 

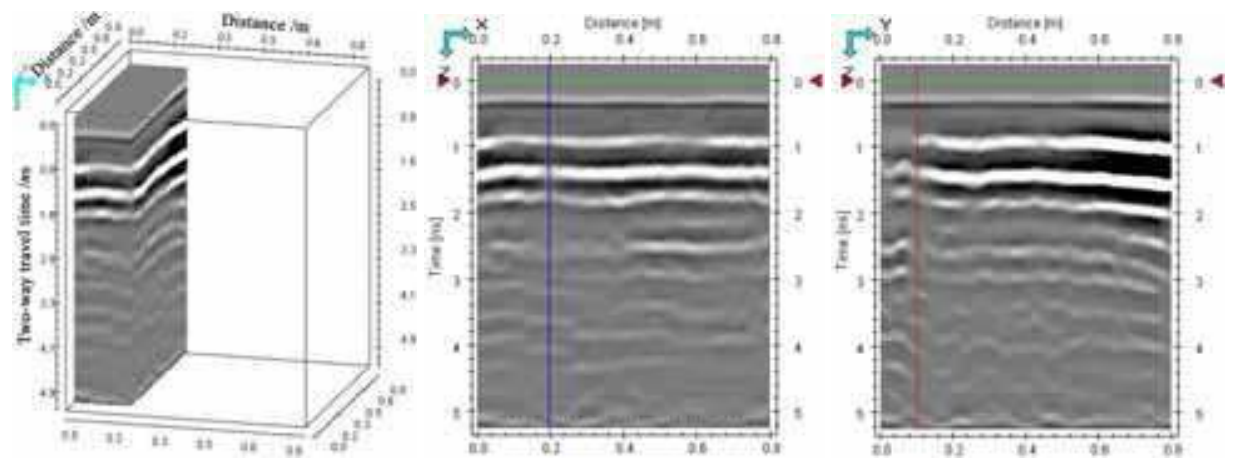

Fig. 19. Typical GPR profiles in illustration of delamination at Mandala Hall

\subsection{Detection in Patala Palace}

The south wall of Western Hall in Potala Palace is selected as the detection area (Fig. 20). From left to right, this area is divided into five square grids with a side length of $80 \mathrm{~cm}$, so that each coverage is $0.64 \mathrm{~m}^{2}$. The spacing distance of both transversal and vertical profiles in grid project is $10 \mathrm{~cm}$ (Fig. 21).

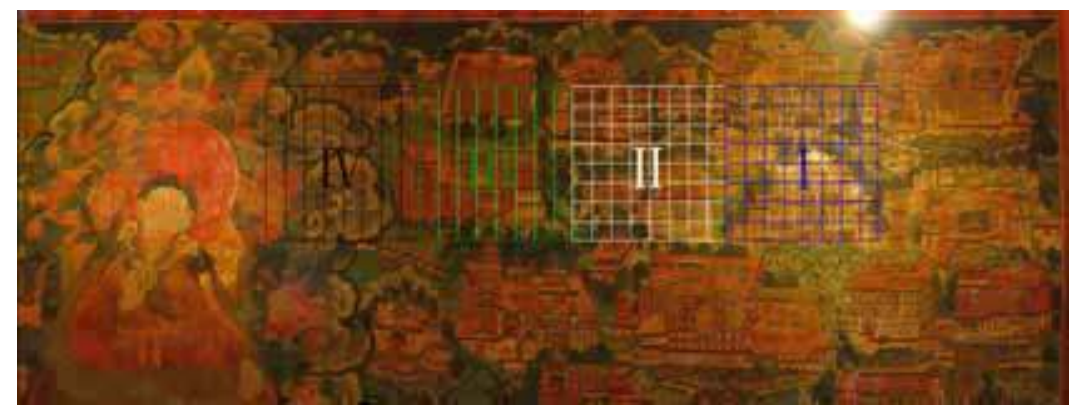

Fig. 20. Detection area in the Western Hall of Potala Palace

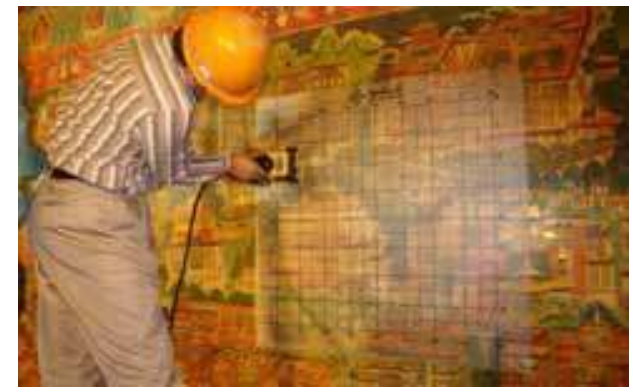

Fig. 21. In-situ orthogonal grid project

In-situ detection test in Potala Palace was carried out on July 10, 2006, the measurement configuration is as follows: sample number is 312 , sampling frequency $28363.966797 \mathrm{MHz}$, 
triggering interval $0.003885 \mathrm{~m}$, and time window 10.999872 ns. The sample number corresponding to the ground surface level is calibrated as 31 .

Raw GPR profile data is digitally processed by the following filters in sequence: automatic gain control (scale: 500000, window: 21), direct current adjustment (start: 207, end: 311), delete mean trace (use entire date), finite impulse response (background: 15, lowpass: 5), and moving average (samples: 3 ). After the post processing as above, the wall made of stone adobe is distinctly illustrated in Fig. 22, since relatively more electromagnetic waves are reflected from the plaster-stone interface.

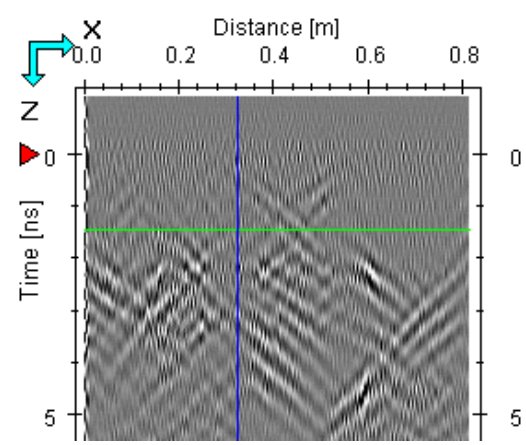

Fig. 22. Plaster-support interface illustrated in radar image

From Fig. 22, it can be seen that when the two-way travel time of electromagnetic wave is near $2 n \mathrm{~s}$, the reflected signal is strong. Suppose that the electromagnetic wave travels at 0.1 $\mathrm{m} / \mathrm{ns}$ in plaster, the thickness of the plaster layer is $10 \mathrm{~cm}$. Besides, the signal of the wave appears unusual at the horizontal distance of $0.42 \mathrm{~m}$, which may be the area of delamination.

If the data in Fig. 22 is only filtered by finite impulse response in Easy 3D, the length of the wooden beam, read as $0.8 \mathrm{~m}$, can be seen clearly in the radar profile (Fig. 23). Furthermore, its width is about $0.28 \mathrm{~m}$ in the side view (Fig. 24).

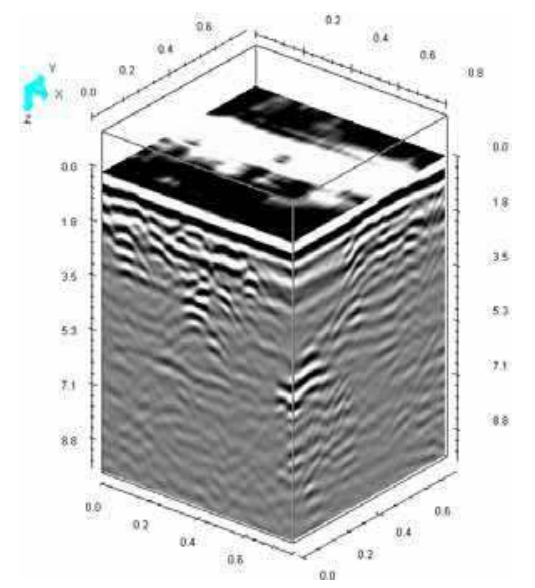

Fig. 23. 3D presentation of underneath beam 


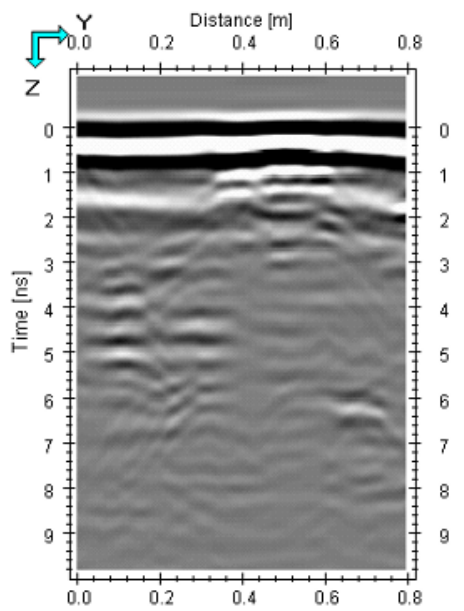

Fig. 24. Width of the wooden beam

To summarize, the deterioration of delamination within the wall paintings is located mainly at the top of the wooden beam and under the plaster layers, and it is $3.2 \mathrm{~m}$ in length, $0.28 \mathrm{~m}$ in width, and $5 \mathrm{~cm}$ in depth from the wall painting surface.

\subsection{Detection in Lashao Temple}

The detection area, $0.8 \mathrm{~m}$ long and $1.2 \mathrm{~m}$ high, in Lashao Temple of Wushan Shuilian Caves is relatively flat, on the north of the lion relief of the Buddha figure (Fig. 25). Altogether, 17 horizontal and 13 vertical profiles (Fig. 26) have been taken, and the distance between adjacent profiles is $0.1 \mathrm{~m}$.

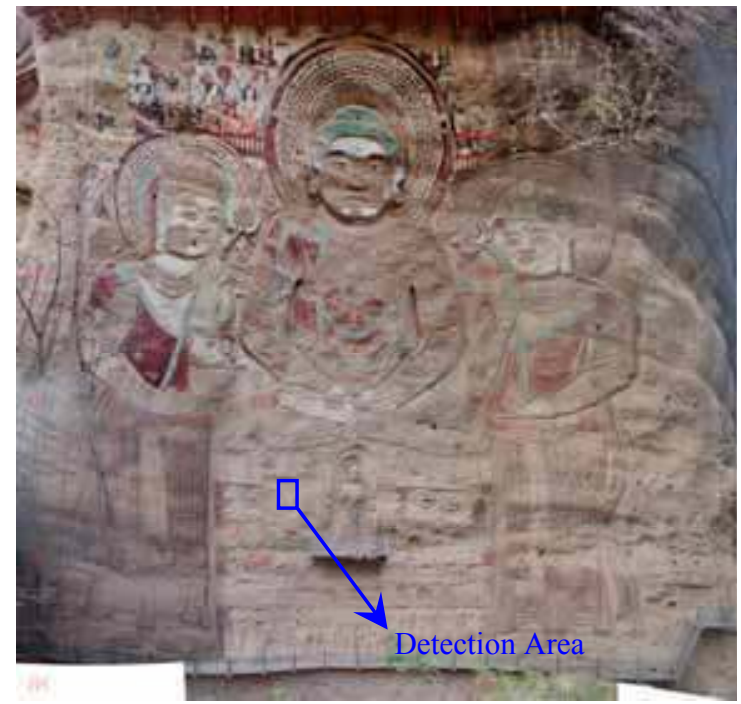

Fig. 25. Overall view of the field test in Lashao Temple 


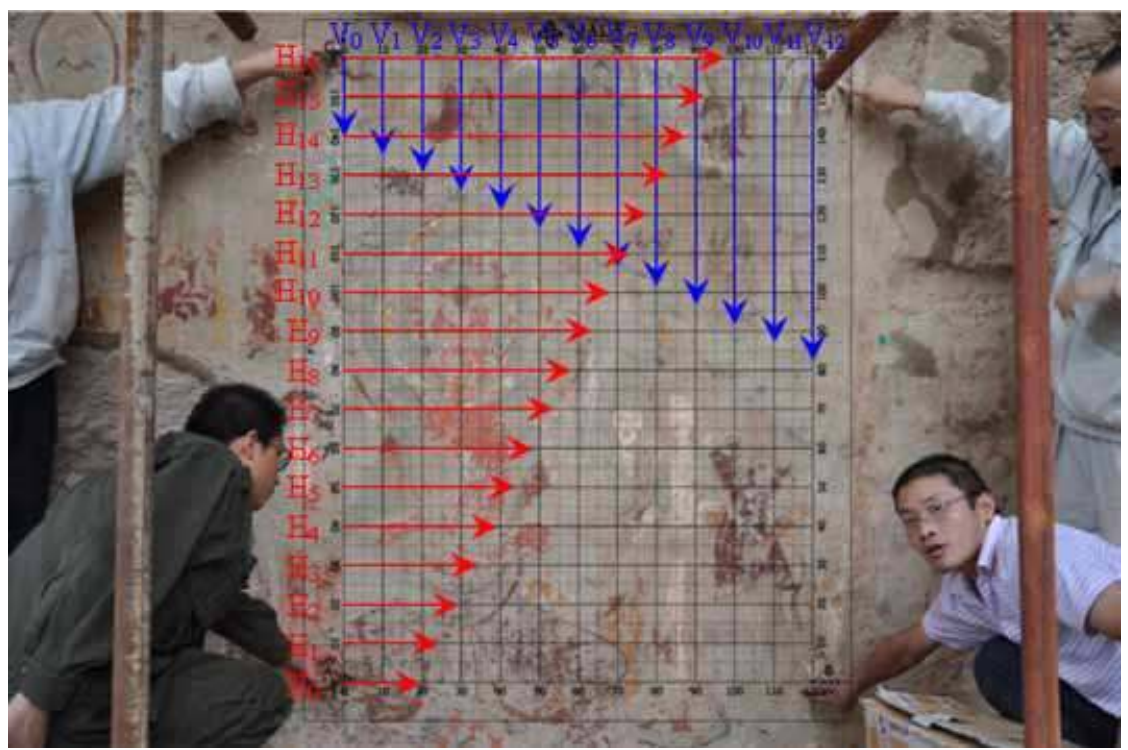

Fig. 26. In-situ detection of delamination in wall paintings in Lashao Temple

As a rule of thumb, the relative dielectric constant of mural plaster is about 1.5 , so that electromagnetic wave travels in plaster layer at the speed of about $2.45 \times 10^{8} \mathrm{~m} / \mathrm{s}(245 \mathrm{~m} / \mu \mathrm{s}$ or $245 \mathrm{~mm} / \mathrm{ns}$ ). In the dialog box of parameter setting, the window of two-way travel time is input as $3 \mathrm{~ns}$, which is equal to set the effective detection depth as $36.75 \mathrm{~cm}$, the sampling frequency is chosen as $142 \mathrm{GHz}$, the interval of impulse triggering time is set as $0.1 \mathrm{~s}$, and the function of automatic stacking is turned on. During the operation of signal processing, the following four filters are loaded: DC Removal, Substract Mean Trace, Band Pass, and Running Average.

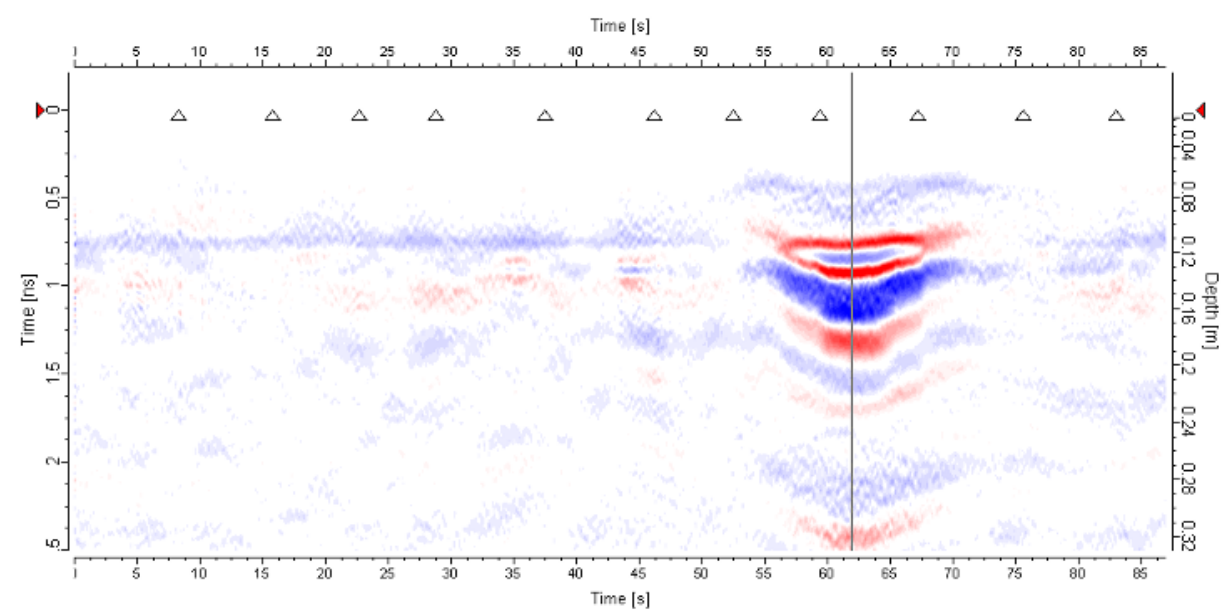

Fig. 27. Presentation of GPR profile $\mathrm{H}_{3}$ 
It is shown in the interpretation results (Fig. 27, Fig. 28, Fig. 29) that the delamination in wall paintings in the detection region is mainly located at the lower left corner, which is in consistence of the area where the loss of mural plasters is serious. In addition, delamination is also serious in the lower right corner and the upper part of detection area. Taking into account that the vertical resolution of RAMAC ground penetrating radar is about $5 \mathrm{~mm}$, delamination in detection area should be more serious (Fig. 30).

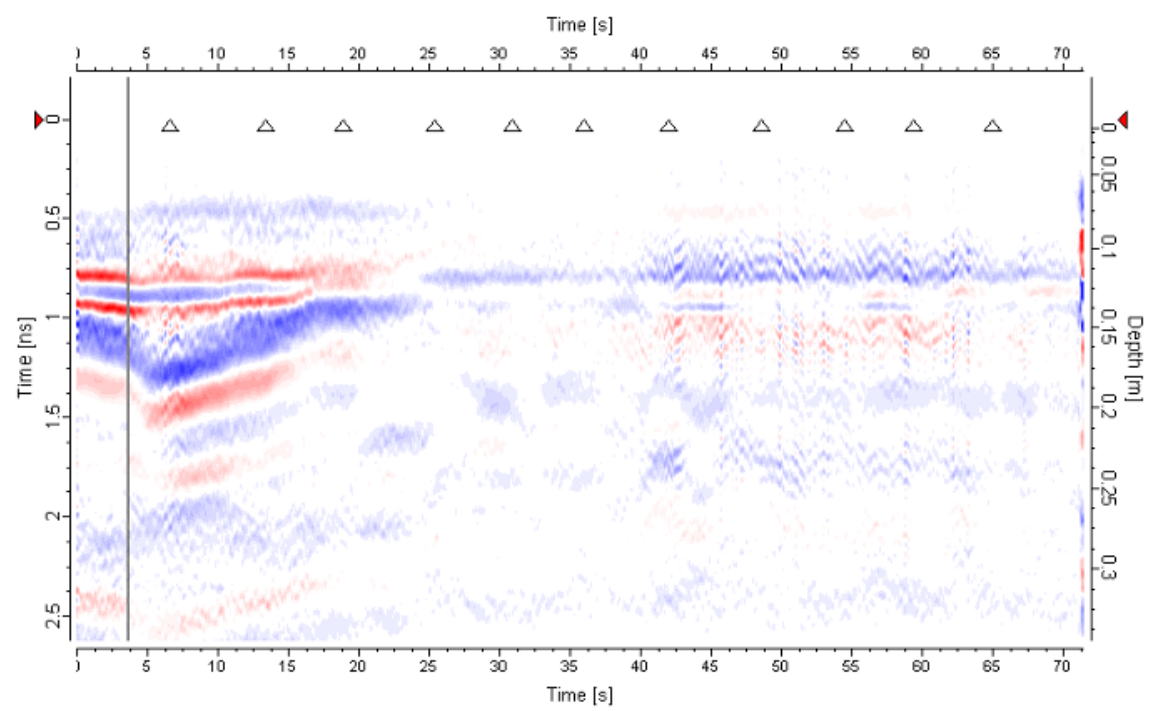

Fig. 28. Presentation of GPR profile $\mathrm{H}_{5}$

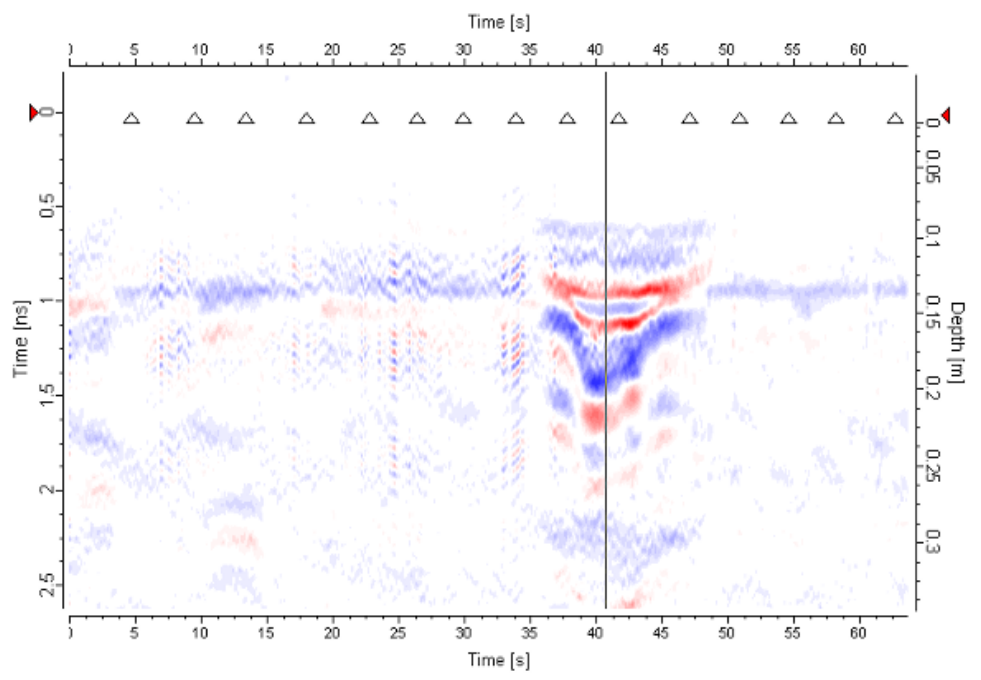

Fig. 29. Presentation of GPR profile $V_{1}$ 


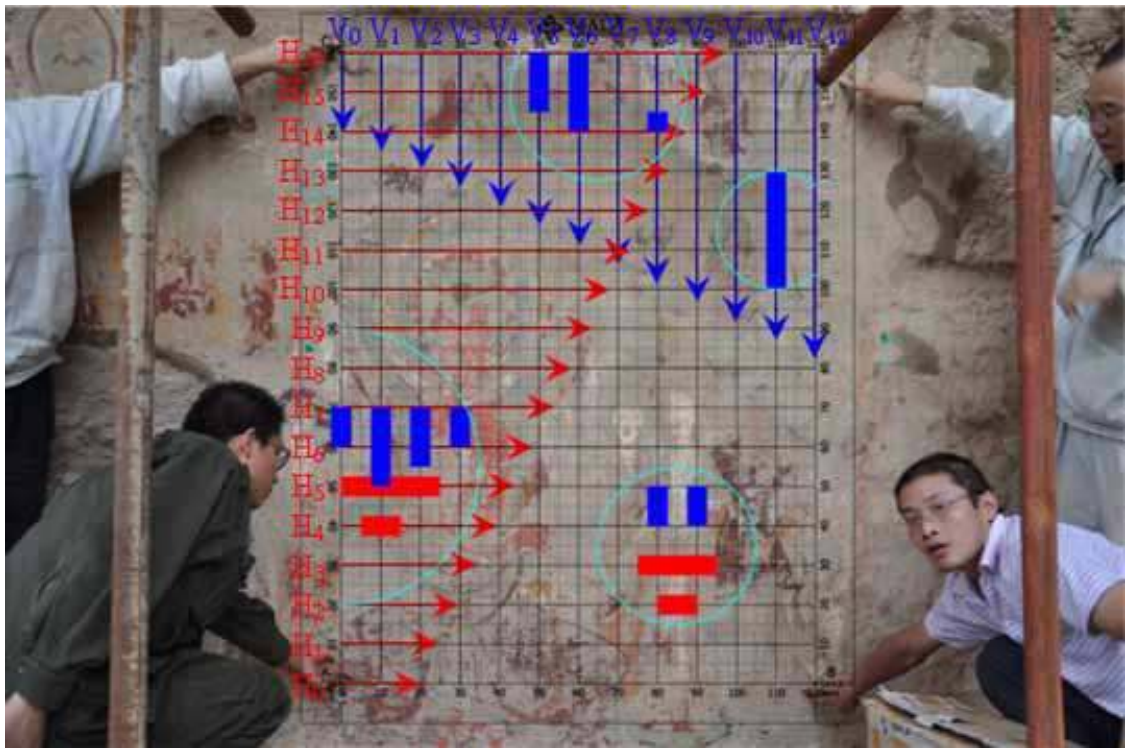

Fig. 30. Comprehensive interpretation of delamination in wall paintings, marked by arc

\section{Conclusion}

Focusing on the propagation of high frequency pulse electromagnetic waves in layered lossy and dispersive medium and after the physical forward modeling experiment, this chapter has successfully located delamination in polished wall paintings by wall coupling antennas using RAMAC ground penetrating radar. It is shown that the ultra-wide band ground penetrating radar is capable of detecting delamination in vertical resolution of about $5 \mathrm{~mm}$ when it is equipped with a transmitting antenna of $1.6 \mathrm{GHz}$ central frequency.

\section{Acknowledgment}

This project is jointly sponsored by State Administration of Cultural Heritage, People's Republic of China in Cultural Heritage Conservation Science and Technology Foundation (No.200101).

The author wishes to thank Dr. Tao YANG of Lanzhou University and Xuebing BAI of Beijing Xing Heng Yun Science \& Trade Co., Ltd. , China for their collaboration and support with the case work. The author is also indebted to Professor Yi SU of National University of Defense Technology, China and Professor Zheng'ou ZHOU of University of Electronic Science and Technology of China for their kind and helpful comments in the preparation of this chapter.

The author is grateful to Professor Zuixiong LI \& Dr. Liyi ZHAO of Dunhuang Academy and all the staff of Conservation Institute and Technical \& Service Center for Protection of Cultural Heritage helped to carry out the lab test and the field test, they are greatly acknowledged for their invaluable logistic support. 


\section{References}

[1] Z. Li, W. Wang, X. Wang, J. Chen, and G. Qiang Ba, Report on Wall Painting Conservation and Restoration Project of Potala Palace, Tibet. Beijing, China: Cultural Relics Press, 2008. ISBN 9787501024704.

[2] W. Wang, Z. Ma, Z. Li, T. Yang, and Y. Fu, Consolidating of Detached Murals through Grouting Techniques, Sciences of Conservation and Archaeology, vol. 18, no. 1, pp. 5259, Mar. 2006. ISSN 1005-1538.

[3] W. Wang, L. Zhao, T. Yang, Z. Ma, Z. Li, and Z. Fan, Preliminary Detection of Grouting Effect on Delaminated Wall Paintings in Tibet Architecture, Chinese Journal of Rock Mechanics and Engineering, vol. 28, supp. 2, pp. 3776-3781, Sep. 2009. ISSN 10006915.

[4] L. Kong, and Z. Zhou, A Effective Method of Improved Resolution for Imaging of Subsurface Ground Penetrating Radar, Signal Processing, vol. 18, no. 6, pp. 505-508, Jun. 2002. ISSN 1003-0530.

[5] Y. Su, C. Huang, and W. Lei, Theory and Application of Ground Penetrating Radar. Beijing, China: Science Press, 2006. ISBN 7030172833.

[6] Z. Li, T. Yang, and W. Wang, Forward Replica Modeling for Detection of Delamination in Wall Paintings with Ground Penetrating Radar, Journal of Engineering Geology, vol. 17, no. 5, pp. 675-681, Oct. 2009. ISSN 1004-9665.

[7] Z. Li, T. Yang, W. Wang, and W. Chen, Detection of Delamination in Tibetan Wall Paintings by Using Ground Penetrating Radar, Journal of University of Electronic Science and Technology of China, vol. 39, no. 6, pp. 865-870, Dec. 2010. ISSN 10088105 . 


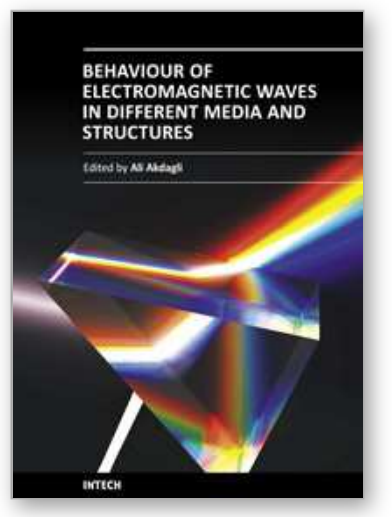

\section{Behaviour of Electromagnetic Waves in Different Media and Structures \\ Edited by Prof. Ali Akdagli}

ISBN 978-953-307-302-6

Hard cover, 440 pages

Publisher InTech

Published online 09, June, 2011

Published in print edition June, 2011

This comprehensive volume thoroughly covers wave propagation behaviors and computational techniques for electromagnetic waves in different complex media. The chapter authors describe powerful and sophisticated analytic and numerical methods to solve their specific electromagnetic problems for complex media and geometries as well. This book will be of interest to electromagnetics and microwave engineers, physicists and scientists.

\section{How to reference}

In order to correctly reference this scholarly work, feel free to copy and paste the following:

Wanfu Wang (2011). Detection of Delamination in Wall Paintings by Ground Penetrating Radar, Behaviour of Electromagnetic Waves in Different Media and Structures, Prof. Ali Akdagli (Ed.), ISBN: 978-953-307-302-6, InTech, Available from: http://www.intechopen.com/books/behavior-of-electromagnetic-waves-in-differentmedia-and-structures/detection-of-delamination-in-wall-paintings-by-ground-penetrating-radar1

\section{INTECH}

open science | open minds

\author{
InTech Europe \\ University Campus STeP Ri \\ Slavka Krautzeka 83/A \\ 51000 Rijeka, Croatia \\ Phone: +385 (51) 770447 \\ Fax: +385 (51) 686166 \\ www.intechopen.com
}

\author{
InTech China \\ Unit 405, Office Block, Hotel Equatorial Shanghai \\ No.65, Yan An Road (West), Shanghai, 200040, China \\ 中国上海市延安西路65号上海国际贵都大饭店办公楼405单元 \\ Phone: +86-21-62489820 \\ Fax: $+86-21-62489821$
}


(C) 2011 The Author(s). Licensee IntechOpen. This chapter is distributed under the terms of the Creative Commons Attribution-NonCommercialShareAlike-3.0 License, which permits use, distribution and reproduction for non-commercial purposes, provided the original is properly cited and derivative works building on this content are distributed under the same license. 